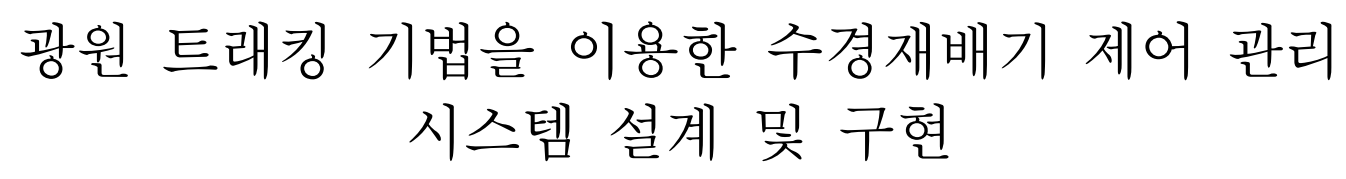

박성균 ${ }^{*}$ 정세훈 ${ }^{* *}$ 오민주 ${ }^{* * *}$ 심춘보 ${ }^{* * * *}$ 박동국 ${ }^{* * * *} \cdot$ 유강수 $^{* * * * * *}$

\title{
A Design and Implementation of Control and Management System for Water Culture Device using Solar Tracking Method
}

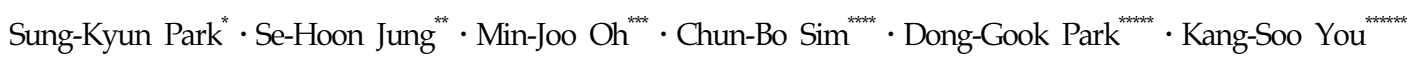 \\ 요 약
}

지구 온난화로 인한 급격한 기후 변화로 인해 단위 면적당 작물의 생산성 향상 및 고품질 작물 재배에 관심이 고조되고 있다. 따라서 본 논문에서는 기존의 담액 수경방식이나 인공광원을 이용한 수경재배 방식이 아닌 광원 트래킹 기법을 적용한 양액 순환 방식의 수경재배기 제어 관리 시스템을 제안한다. 제안하는 수경재배기는 일정 한 양의 양액과 물을 수로로 흘려보내 순환시키는 형태인 양액 순환 방식과 수경재배기 하단 부분의 작물도 지속 적인 광합성 작용이 가능 하도록 피라미드 형태의 다단구조식으로 설계한다. 아울러 광원 트래킹 기법은 기존 2 축, 4축 센서 방식이 아닌 태양광의 그림자를 추적하기 위한 중심축 센서 방식의 5축 센서 방식으로 설계한다. 본 논문에서 제안한 수경재배기를 통해 기존 연구에서 소개되지 않은 광원 트래킹 기법은 작물에 지속적인 광합성 작용으로 작물의 생장 속도를 단축시킬 수 있었으며, 피라미드형태의 다단식구조로 상, 하단 구분 없이 모든 작물 이 동일한 형태의 생육환경을 제공받을 수 있어 단위 면적당 높은 작물 생산량이 예상된다.

\section{ABSTRACT}

It is throwing the spotlight on the cultivation crops about high quality crops and productivity improvement per unit area because of rapid climate change caused by global warming. Therefore, we propose a water culture management of circulation nutrient method control system applies to solar tracking method not using traditional method of deep flow technique and artificial light source. We design it in the form of the circulation nutrient method in waterway of a certain amount of nutrient solution and water flowed into the way of circular. In addition, we design a multistage structure in pyramid shape which be possible continuous photosynthesis action to crops of water culture bottom part. Also, solar tracking method is designed five sensor method of center hole sensor method for tracking shadow of solar light not using traditional two hole, four hole sensor method. Finally, through the water culture device applies to solar light tracking method was not introduced in existing study yet, we can reduce growth speed of crops which be possible continuous photosynthesis action to crops. Moreover, We can expect high productivity of per unit area which be possible all crops can be offered growth environment of same type by using form of pyramid shape of multistage structure without top or bottom part.

\section{키워드}

Water Culture, Circulation Nutrient, Solar Tracking, Object Oriented Modeling 수경재배, 양액순환, 광원트래킹, 객체지향모델링

* (주) 휴머닉스 대표이사(psk1227@nate.com)

** 순천대학교 멀티미디어공학과 박사과정(iam1710@hanmail.net)

*** 순천대학교 멀티미디어공학과 석사과정(minjoo8410@naver.com)

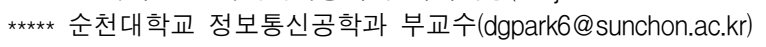

****** 전주대학교 교양학부 교수(gsyou@jj.ac.kr)

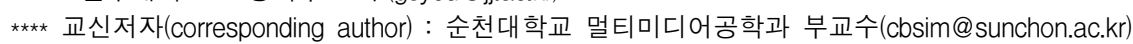

접수일자 : 2013. 11. 26

심사(수정)일자 : 2013. 12. 21

게재확정일자 : 2014. 02. 11 


\section{I. 서 론}

최근 환경의 변화로 인한 지구상의 기후변화로 급 격한 기온변화, 초강력 태풍발생, 극심한 가뭄, 폭설등 다양한 형태의 자연재해가 빈번하게 발생하고 있다. 특히 대한민국의 지리적인 특성상 계절별 자연재해는 1 년 내내 이어지고 있다. 이로 인하여 작물들의 피해 는 계절별로 발생하고 있으며, 해년마다 작물 피해 복 구 후 다시 피해를 보는 현상이 되풀이 되면서 작물 부족 및 비용 상승의 원인이 되고 있다. 이러한 현상 들 때문에 1 년 내내 안정적인 작물의 수확과 공급을 통한 작물 가격 안정을 위한 연구가 필요한 실정이다. 이러한 안정적인 작물 공급 관리를 해결하기 위한 한 가지 해결 방안으로는 식물공장과 수경재배기와 같은 최적 생장 작물 관리 시스템 및 농업 시스템 제어에 대한 연구가 주목받고 있는 실정이다[1-5].

기존에 연구된 수경재배기는 인공광원(LED) 및 일 자형 다단 구조 방식을 활용한 담액수경방식의 연구 가 대부분이다. 이는 구조물 특성상 상단 부분은 인공 광원의 영향을 많이 받지만 하단 부분으로 내려갈수 록 인공광원의 영향이 못 미치는 문제점이 지적되고 있다. 이는 단위 면적당 높은 농작물 생산율을 요구하 는 수경재배 시스템의 장점과 배치되는 부분이다. 또 한 수경재배기의 특성상 수로를 통한 물의 공급만 고 려하여 작물의 광합성 작용에 대한 연구는 미비하다 는 지적이 있다.

그리고 본 논문에 적용되는 태양 트래킹 기술은 태 양광원의 위치를 센서로 확인하고 해당 태양의 위치 로 추적하는 기술이다. 태양 트래킹 기술의 보편적인 연구 방식은 프로그램 방식과 센서방식이 존재하며 센서방식은 2축, 4축 방식에 대한 연구가 대부분이다. 2축, 4축 방식은 태양의 일출에서 일몰까지 연속적으 로 트래킹한다. 이는 일반적으로 광센서 2개 이용하여 트래킹이 단순하고 가격이 저렴한 반면에 계절에 따 른 광원의 고도각이 바뀔 때 이를 트래킹할 수 없다 는 단점을 가지고 있다.

이에 본 논문에서는 기존에 연구된 수경재배기의 단점 광원 트래킹 기술의 단점인 기존의 일자형 다단 구조 방식의 문제점을 효율성 측면으로 접근하여 계 절과 시간에 영향을 구애받지 않는 태양 트래킹 기술 기반의 수경재배 제어 관리 시스템을 제안한다. 기존
의 1 축, 2 축 센서방식이 아닌 5 축 센서방식을 적용한 광원 트래킹 모듈기반의 수경재배 제어 관리 시스템 을 설계 및 구현한다.

본 논문의 구성은 다음과 같다. 2장에서는 관련연 구를 제시하며, 3장에서는 시스템의 재활용성[6-7]을 위해 객체지향 설계 모델링을 기반으로 광원 트래킹 기술을 적용한 수경재배 제어 관리 시스템을 설계한 다. 4장에서는 제안된 시스템의 구현 GUI 및 수경재 배 $\mathrm{H} / \mathrm{W}$ 를 제시하며, 마지막으로 5장에서는 결론 및 향후 연구방안으로 마무리한다.

\section{II. 관련 연구}

이번 장에서는 기존 연구된 수경재배 제어 관리 시 스템 및 광원 트래킹 기술을 소개하며 기존 연구의 문제점을 분석한다.

[8]의 연구에서는 광원 트래킹 시스템 분류의 프로 그램 방식을 이용한 광원 트래킹 시스템을 제안하였 다. 또한 기존 연구와의 차별성을 위하여 프로그램 방 식과 혼합한 전력 추적 혼용방식을 제시하였다. 이를 위해 위도, 경도, 시간변수를 활용하여 태양의 궤적을 추적하는 방법을 활용하였다. 해당 연구에서 태양광의 위치를 계산하여 황도에 따라 셀을 이동하는 메커니 즘 중 황도 설정은 GPS(Global Positioning System) 에 의해서 방위각, 고도각을 통해 계산하게 된다. 최 대 전력점 제어(MPPT; Maximum Power Point Tracking)를 전력변환기와 트래킹장치로 일체화하였 으며, 센서노화 및 오작동에 의한 단점을 극복하였다. 또한 시스템 초기 자동 셋팅이 가능하다는 장점을 제 시하였다.

[9]의 연구는 완전 제어형 식물공장 운영에 사용되 는 각각의 모듈단위의 센서, 제어기를 하나의 통합센 서 및 제어기로 제작하여 완전 제어형 식물공장에 최 적화된 제어 시스템을 제안하였다. 식물공장의 광(조 도), 온도, 습도, 이산화탄소, 기류, 양액 데이터를 측 정하고 데이터 전송을 위한 각각의 데이터로거가 필 요하지만 해당 연구에서는 이를 통합하여 하나의 제 어기로 처리할 수 있는 방법을 제시하였고, 이는 기존 식물공장 구축비용보다 약 60 70\% 정도의 비용 절 감 효과를 가져왔다. 또한 해당 연구에서는 $\mathrm{LED}$ 의 
주파수 $(1 \mathrm{~Hz} \sim 30 \mathrm{KHz}), \quad \operatorname{Duty}(1 \% \sim 100 \%)$, 전류(0A $3.5 \mathrm{~A}$ ), 파장(적색 $660 \mathrm{~nm}$, 청색 $450 \mathrm{~nm}$, 녹색 $425 \mathrm{~nm}$ )을 제어하여 작물의 생육 환경을 보다 세밀하게 제어할 수 있다는 장점을 증명하였다.

[10]의 연구에서는 태양광을 활용한 신재생 에너지 기반의 식물공장 성장환경 제어 관리 시스템에 관한 연구를 제안하였다. 신재생 에너지로 광원을 활용한 해당 연구에서는 인공광원인 $\mathrm{LED}$ 발열로 인한 공조 기 가동 시간 감소와 일사량 증가로 인한 생육, 생산 량 증대를 목적으로 하고 있다. 이를 위해 해당 연구 에서는 과채류의 최적 생장용 $\mathrm{LED}$ 및 $\mathrm{LED}$ 광원 제 어를 위하여 PWM(Pulse Width Modulation)기술을 이용한 조도 및 광합성 센서와 연계한 광원 제어 기 술을 제시하였다. 최적 생장용 LED 제어부의 제어채 널은 총 7 개의 채널로 구성되며 적색, 청색, 흰색에 각각 1 채널씩 사용하였고 나머지 4개는 혼합채널로 사용하였다. LED 제어방식은 PWM Dimming Constant Current Control방식을 활용하여 일정 DC레 벨을 유지시켜 효율을 향상시키도록 하였으며, $\mathrm{PC}$ 와 의 인터페이스는 RS-485를 사용하여 광량, 파장 및 주파수를 제어하도록 하였다. 광량은 적색과 청색 $\mathrm{LED}$ 각각 0 100\%를 $1 \%$ 단위로 제어 가능하고, 파 장은 적색 및 청색 LED 범위는 0:100 100:0로 1\% 단위의 제어가 가능하며, 주파수는 $0.1 \sim 10 \mathrm{KHz}$ 범위 를 $0.1 \mathrm{KHz}$ 단위로 제어가 가능하도록 하였다.

\section{III. 광원 트래킹 기법을 이용한 수경재배 제어 관리 시스템}

수경재배 제어 관리 시스템 하드웨어[11]의 하단에 는 광원 트래킹 모터를 구축하고 상단에 설치된 조도 센서를 이용하여 태양광을 추적한다. 수경재배 제어 관리 시스템 하드웨어가 상, 하, 좌, 우로 광원량에 따 라 이동하게 하게 된다. 본 논문에서는 태양광의 직진 성을 활용하기 위하여 직육면체의 하단 부분을 제외한 육각형의 5 면에 각각 광센서를 부착하였다. 수경재배 제어 관리 시스템 관리 서버는 하드웨어에서 수집 전 송된 각종 데이터를 Wifi 통신으로 실시간 전송 받아 데이터를 파싱하고 실시간 정보를 데이터베이스에 저 장하게 된다. 수경재배 제어 관리 시스템 UI는 관리자
및 사용자에게 종합 제어 관리 서비스를 제공한다. 관 리자는 실시간 센서정보와 수위정보를 확인할 수 있으 며, 사용자 는 데이터베이스에 입력된 실시간 생육 환 경 정보를 웹, 모바일 인터페이스로 수경재배 제어 관 리 시스템의 상태 정보를 제공한다. 또한, 웹, 모바일 인터페이스에서는 수경재배 제어 관리 시스템 하드웨 어에 대한 LED, 트래킹. 펌프, 히터등을 제어할 수 있 도록 하였다. 그림 1 은 제안하는 광원 트래킹 기반의 수경재배 제어 관리 시스템의 전체 구조도이다.

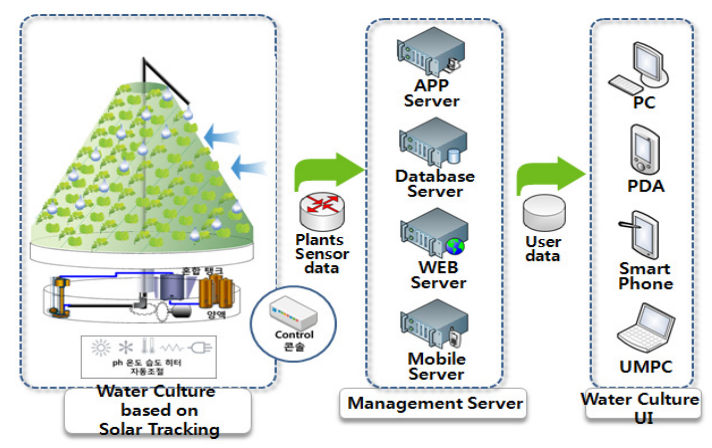

그림 1. 제안하는 시스템의 전체 구조

Fig. 1 Overall structure of proposed system

\section{1. 광원 트래킹 $\mathrm{H} / \mathrm{W}$ 모듈 설계}

제안하는 수경재배 제어 관리 시스템 하드웨어는 태양광을 추적하기 위한 알고리즘 방법인 프로그램방 식과 센서방식 중 광량의 차이를 추적하는 센서방식 을 활용한다. 그리고 기존 연구 방식인 2축, 4축 센서 에 기본 광량을 측정할 수 있는 센서를 추가한 5축 센서방식을 제안한다. 그림 2 는 본 논문에서 제안하는 방식으로 직육면체의 하단부분을 제외한 5 면에 센서 를 부착하는 방식을 위치별로 도식화한 것이다.

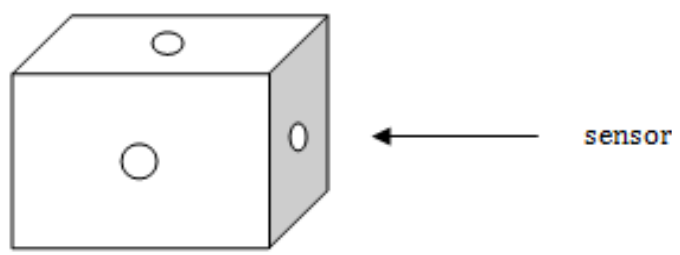

그림 2. 광센서를 이용한 5축 센서 모형 설계 Fig. 2 Design of five axis sensor type using light sensor 
광센서는 직육면체의 동서남북 방향으로 해당면의 중앙 4 곳에 부착하고 각 면의 센서위치는 지상으로부 터 45도 방향으로 설치하여 직육면체의 벽면으로부터 발생하는 그림자에 따라서 광량을 측정하도록 설계한 다. 실제 태양광의 방향은 직선성이 강하므로 지구와 태양의 고도에 따라 그림자가 발생하는 원리를 이용 하여 태양의 위치를 추적한다. 제안된 방식을 통하여 태양의 일사량이 광센서에 도달하는 빛의 양과 비례 하여 측정할 수 있다. 그림 3 은 광센서의 위치를 나타 낸 것이며, a1, b1, a2, b2 는 태양으로부터 입사되는 광량을 전기신호를 나타내고 식 1 및 식 2 의 $e_{x}(t)$, $e_{y}(t)$ 는 각각 좌우 $(\mathrm{x})$, 상하 $(\mathrm{y})$ 값의 편차를 표현하고 비교된 값은 많은 양으로 입사되는 전기적신호의 위 치로 추적하게 된다. 여기서 추적되는 오차를 줄이기 위해서 $\mathrm{Op}^{-} \mathrm{amp}$ 에 입력되는 저항의 값(VR6)을 조정 하여 전기적신호로 변환하고 어떠한 환경에서도 최적 화된 값을 얻도록 설계하였다. 일정크기의 일사량에서 상하 좌우의 센서에서 출력되는 전기적신호를 $\mathrm{A} 1$, $\mathrm{A} 2, \mathrm{~B} 1, \mathrm{~B} 2$ 라고 한다면 정규화된(normalizing) 식 3 및 식 4에서는 각각 좌(식 1), 우(식 2), 상(식 3), 하 (식 4) 방향의 센서에서 출력되는 정규화된 신호의 차를 나타낸다.

$$
\begin{aligned}
& e_{x}(t)=a_{1}(t)-a_{2}(t) \\
& e_{y}(t)=b_{1}(t)-b_{2}(t) \\
& e_{x}(t)=\frac{a_{1}(t)}{A_{1}}-\frac{a_{2}(t)}{A_{2}} \\
& e_{y}(t)=\frac{b_{1}(t)}{B_{1}}-\frac{b_{2}(t)}{B_{2}}
\end{aligned}
$$

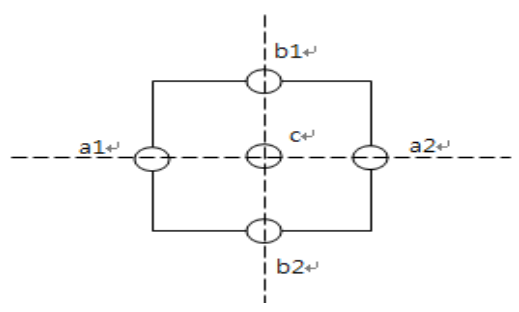

그림 3. 광센서의 위치

Fig. 3 Location of light sensor
그림 4에서 광센서의 위치로부터 45도 각도의 위치 에서 입사되는 광량을 입사되는 값을 벡터로 표현하 였으며, 이는 식 5 및 식 6 과 같이 최종 정규화된 값 을 표현할 수 있다.
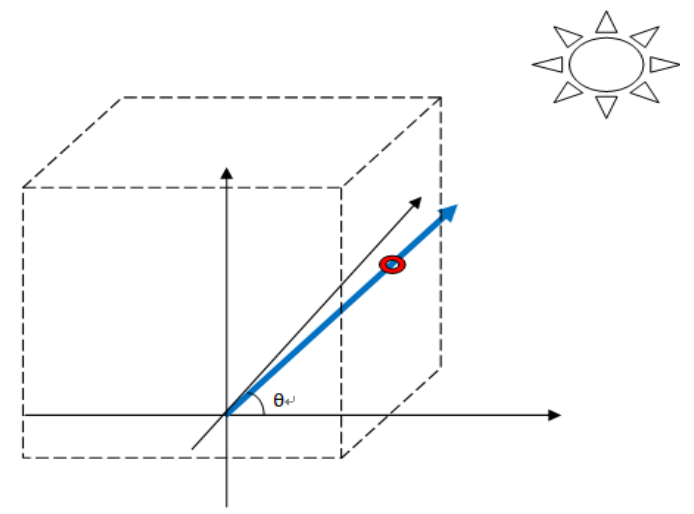

그림 4. 태양광 신호 출력 예시

Fig. 4 Example of solar light signal output

$$
\overline{e_{x}(t)}=\frac{a_{1}(t)}{A_{1}} \cos 45^{\circ}-\frac{a_{2}(t)}{A_{2}} \cos 45^{\circ}
$$

$\overline{e_{y}(t)}=\frac{b_{1}(t)}{B_{1}} \cos 45^{\circ}-\frac{b_{2}(t)}{B_{2}} \cos 45^{\circ}$

그림 5 는 태양광 입사 후 보정값과 위치추적까지의 알고리즘을 도식화한 것이다. 각 면의 중앙에 위치한 광센서는 현재 들어오는 빛의 총량을 감지하여 낮과 밤의 차이를 식별한다. 그리고 날씨의 상관관계 및 태 양광뿐만 아니라 최적화된 빛으로 추적한다. 센서에서 들어오는 태양광량의 전기적신호와 이를 보정하기 위 한 보정값을 합산하여 컨트롤러에 전달된다. 이를 통 해 모터제어를 처리하며 최종적으로 태양광의 위치를 추적하게 된다.

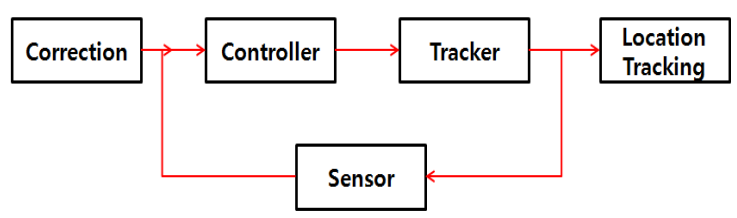

그림 5. 태양광 위치추적 알고리즘

Fig. 5 Solar light location tracking Algorism 
그림 6은 컨트롤러의 제어를 위한 프로그램 소스코 드이다. 컨트롤러 제어는 광량의 차이에 따른 모터 구 동 및 상하좌우 제어를 통해 측정 범위를 벗어나지 못하게 제어하는 코드의 일부분이다.

LR1 = s_l-s_r;

// Analysis of the difference between the light amount of the left and right sensor

$$
\text { if(LR1 }>=\text { cha })
$$

// Setup calibration value of the Left and right sensor

$$
\text { if }\left(\mathrm{s} \_1>=\text { s_r }\right)
$$

// If light amount of left sensor is larger than right sensor

$$
\text { if ( limit_r }==1 \text { ) }
$$

// Checking the status of the right limit switch

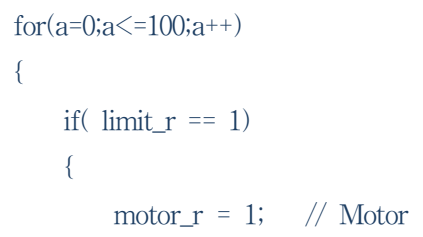

그림 6. 광원 트래킹 및 Limit $S / W$ 제어 코드 Fig. 6 Solar light tracking and Limit S/W control code

그림 7은 수경재배 제어 관리 시스템의 광원 트래 킹 메인회로도 $\mathrm{PCB}$ 화면이다. 메인 $\mathrm{CPU}$ 는 $\mathrm{Atm}^{-}$ ega128을 활용하여 설계하였고, 제어버튼 회로도, 통 신 모듈 회로도, USB 연결 회로도, LCD Display, 트 래킹 모터 연결 회로도, 광원 분석 회로도, 수동/자동 제어 회로도 등이 포함되어 있다.

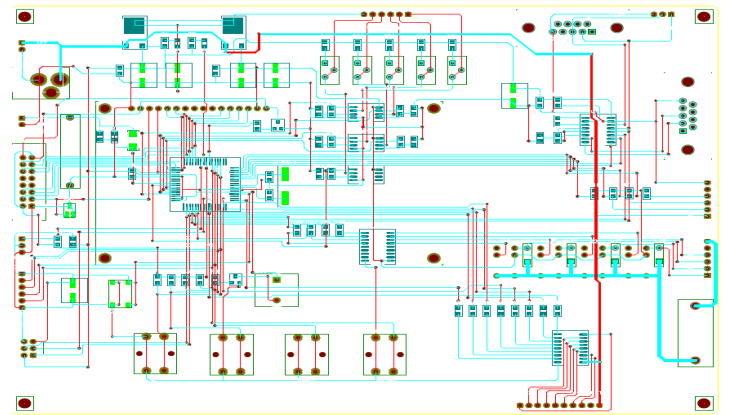

그림 7. 광원 트래킹 $\mathrm{CPU} \mathrm{PCB}$ 설계

Fig. 7 Design of solar light tracking CPU PCB

\section{2. 수경재배 제어 시스템 인터페이스 설계}

제안하는 시스템의 인터페이스 모듈은 크게 웹 사 용자 인터페이스, 모바일 사용자 인터페이스로 구성된 다. 웹 사용자 인터페이스는 JSP기반의 센서정보 확 인 및 제어가 가능하도록 하였다. 그리고 모바일 사용 자 인터페이스는 안드로이드기반으로 웹 사용자 인터 페이스와 동일한 센서정보 확인 및 제어가 가능하도 록 하였다. 또한 인터페이스 설계는 객체지향 설계 모 델링기법을 이용한다.

\subsection{1. 웹 사용자 인터페이스}

그림 8은 실시간으로 업데이트 되는 생육 환경 데이 터를 기반으로 사용자 알림 서비스를 제공하는 흐름을 동적으로 표현하는 시퀀스 다이어그램이다. USER는 request 메소드로 웹 페이지의 Main 객체를 확인하며 수경재배 제어 관리 시스템 하드웨어에서 업데이트 되 는 각종 센서 데이터를 확인한다. 모든 센서데이터는 hardwaresorting 메소드를 요청하며 하드웨어 일련번 호로 구분한 각 정보를 하나씩 필터링하는 SensorData 객체를 이용한다. 일련의 센서데이터는 디폴 트 센서데이터와 비교하기 위하여 compare 객체에 requesting 메소드를 전달한다. 만약 위험 수치에 도 달하지 않을 경우 fail 메소드와 failresult 메소드를 통해 결과값을 Main 객체에 전송하게 된다. 그러나 위험 수치에 도달할 경우 해당 센서데이터를 DBMS 에 저장하게 되며, alerttrans 메소드를 Alert 객체에 전달하게 된다. Alert 객체는 alertresult 메소드와 alertresponse 메소드를 통해 USER에게 경고 알림과 경고 데이터를 전송하게 된다. 


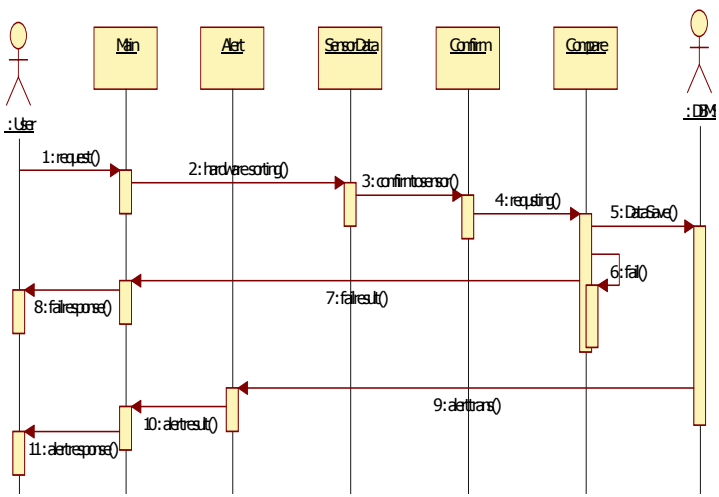

그림 8. 웹 인터페이스 시퀀스 다이어그램 (센서정보 알림)

Fig. 8 Web interface sequence diagram (sensor information alarm)

웹 인터페이스의 클래스는 총 20 개의 클래스를 구 성되어 있다. 웹 사용자를 위한 JSP 페이지는 Model2 인 MVC(Model-View-Controller)구조를 활용하여 서 블릿과 JSP에게 서로 역할을 나누었다. Model의 역할 을 하는 $\mathrm{DB}$ 는 수경재배 제어 관리 시스템 데이터베 이스를 관리하고 통신작업 수행과 비즈니스 로직을 수행한다. View의 역할을 하는 JSP페이지에서는 사 용자가 웹 페이지에 접근하기 위한 웹페이지의 GUI(Graphic User Interface)를 제공한다. Controller 에서는 수경재배 제어 관리 시스템 사용자에게 제공 한 GUI에서 입력받은 데이터를 비즈니스 로직기능에 전달하고 결과물을 매핑시킨다. Controller에 해당하는 ControllerTemplateServlet은 JSP페이지에서 수경재배 제어 관리 시스템 사용자의 데이터의 검색 및 조회 요청을 처리하고 $\mathrm{JSP}$ 페이지에서 사용될 클래스들의 인스턴스를 만든다. 그리고 요청에 따른 JSP페이지의 이동도 담당하고 있다. MODMYDataBean은 MODMYDBBean클래스에서 생성되고 DTO(Data Transfer Object)로 데이터베이스에 있는 각 칼럼에 해당하는 데이터객체들을 가져온다. MODMYDBBean은 DAO (Data Access Object)로 데이터베이스에 연결하여 MODMYDataBean의 객체를 데이터베이스에 수정, 삭제, 입력 처리한다. 그림 9 는 JSP기반의 웹 인터페 이스의 센서정보 알림 기능의 클래스 다이어그램이 다.

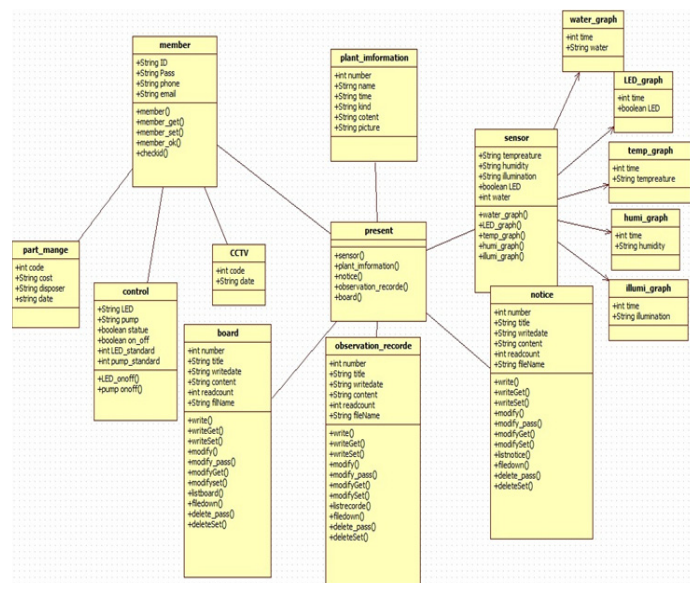

그림 9. 웹 인터페이스 클래스 다이어그램 (센서정보 알림)

Fig. 9 Web interface class diagram (sensor information alarm)

\subsection{2. 모바일 사용자 인터페이스}

그림 10은 안드로이드기반의 모바일 인터페이스의 수경재배기 제어 기능 및 센서정보 확인 등의 기능을 처리할 수 있는 모바일 클래스 다이어그램이다. 모바 일 인터페이스는 총 15 개의 클래스로 구성되어 있다.

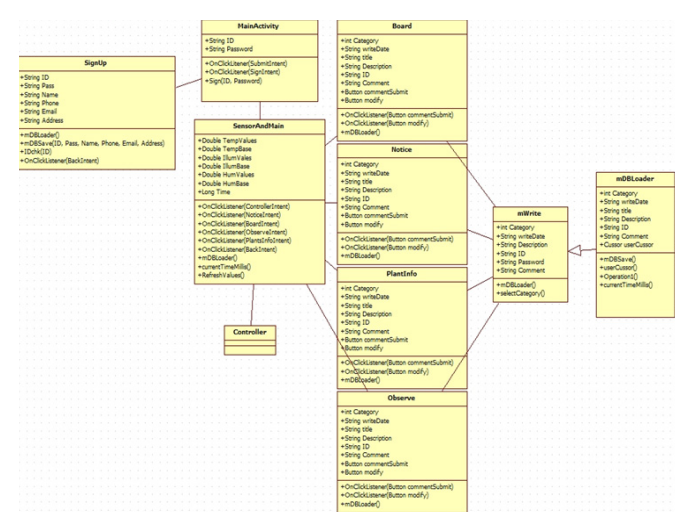

그림 10. 모바일 인터페이스 클래스 다이어그램

Fig. 10 Mobile interface class diagram

모바일 인터페이스인 안드로이드기반의 스마트폰에 서 서비스의 동작은 액티비티 호출과정으로 이루어져 있고 액티비티의 호출과 반환은 스택 형식으로 이루 어져 있어 한 개의 액티비티가 다른 액티비티를 호출 할 때 액티비티가 스택영역에 하나씩 쌓이게 된다. 모 
바일 서비스에 접속하면 intro 클래스를 호출하여 onCreate 메서드를 재정의하고 모바일 프로세스를 초 기화하게 된다. 그리고 onTouch 이벤트 메서드는 메 인 MainActivity 클래스를 호출하고 파서를 이용하여 웹서비스에서 제공하는 수경재배 제어 관리 시스템의 모든 센서정보 및 제어 데이터, 식물정보 등을 $\mathrm{XML}$ 형식으로 받아오게 된다. 모바일에서는 SensorAndMain 액티비티에 저장된 모든 센서값을 한 번에 볼 수 있고, 수경재배기를 제어하기 위한 모바일 페이 지로 이동할 수 있다. 게시판에는 4개의 탭으로 각각 게시판, 공지사항, 식물정보, 관찰일지를 포함하고 있 으며, 모바일에서 작성된 데이터는 안드로이드에서 $\mathrm{SQL}$ 에 접근하여 값을 보낼 수 있도록(데이터파싱) $\mathrm{mDBLoader}$ 라는 클래스를 정의한다. 서버로의 저장은 $\mathrm{mWrite}$ 액티비티의 저장에 해당하는 이벤트발생 시 호출된다.

\section{3. 데이터베이스 스키마}

그림 11은 본 논문에서 제안한 수경재배 제어 관리 시스템의 스키마이다.

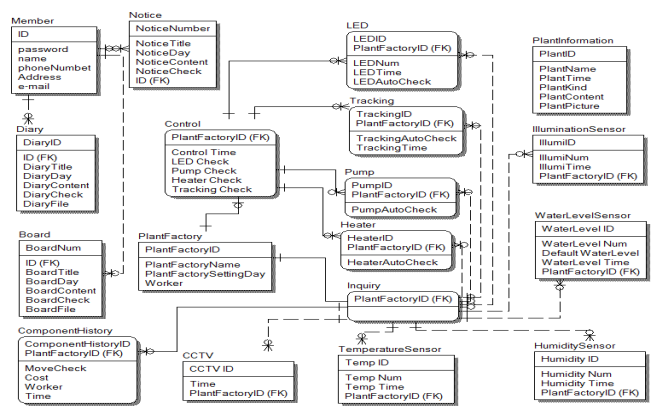

그림 11. 제안하는 시스템 데이터베이스 스키마

Fig. 11 Proposed system database schema

시스템에서 사용되는 데이터베이스는 총 18 개의 테 이블로 구성되어 있다. 시스템 사용을 위한 Member 테이블은 사용자의 이름, 아이디, 연락처가 저장되어 있는 테이블이다. 해당 테이블은 Board 테이블, Diary 테이블, Notice 테이블과 1 대N의 관계를 통해 사용자 가 여러 개의 게시판, 공지사항, 관찰일지를 활용할 수 있다. PlantFactory테이블은 최적 생장 작물 관리 시스템의 하드웨어를 구분하기 위한 테이블로써 해당
테이블에는 구분 $\mathrm{ID}$, 이름, 설치일자, 작업자 등의 정 보를 포함하고 있다. 또한 PlantFactory테이블은 Control테이블과 Inquiry테이블간의 식별관계를 통해 해당 하드웨어의 제어와 센서값 조회등을 연결할 수 있도록 하였다. 하드웨어에 대한 센서값은 총 9 개의 테이블 $\mathrm{LED}$, 온도, 조도, 습도, 수위, 펌프, 히터, $\mathrm{CCTV}$, 트래킹에 대한 정보 테이블을 포함하고 있으 며, Inquiry테이블을 통해 각 센서의 조회가 가능하다. Control테이블은 LED테이블, Tracking테이블, Pump 테이블, Heater테이블과 식별관계를 통해 최적 생장 작물 관리 시스템 하드웨어에 대한 제어가 가능하도 록 하였다. 마지막으로 PlantInformation테이블은 식 물 정보를 나타낸다.

\section{IV. 구현 및 성능평가}

\section{1. 구현 환경}

제안하는 시스템의 설계 및 구현 환경은 표 1 과 같다.

표 1. 설계 및 구현 환경

Table 1. Design and implementation environment

\begin{tabular}{c|c}
\hline Item & Content \\
\hline \hline OS & Windows7 Professional SP1 \\
\hline S/W Design & $\begin{array}{c}\text { StarUML, Microsoft Visio 2007, } \\
\text { Er-Win 4.0 }\end{array}$ \\
\hline H/W Design & ArtWork, OrCad Rayout \\
\hline DBMS & MS-SQL 2005 \\
\hline $\begin{array}{c}\text { S/W } \\
\text { Implementation } \\
\text { Tool }\end{array}$ & Eclipse Galileo, Google Android 2.3 \\
\hline H/W CPU & ATmega 128 \\
\hline $\begin{array}{c}\text { Tracking } \\
\text { Module }\end{array}$ & ST-7L(3AW4C02) \\
\hline $\begin{array}{c}\text { Communication } \\
\text { Module }\end{array}$ & Wiz 6000, NT-USB2UART \\
\hline
\end{tabular}

\section{2. 시스템 구현}

\subsection{1. 양액순환방식 수경재배기}

그림 12 는 본 논문에서 제안된 수경재배기 구조의 
전체적인 모습이다. 기존에 연구된 담액수경방식과 물 의 흐름을 연결한 흘림방식의 혼합형이다.

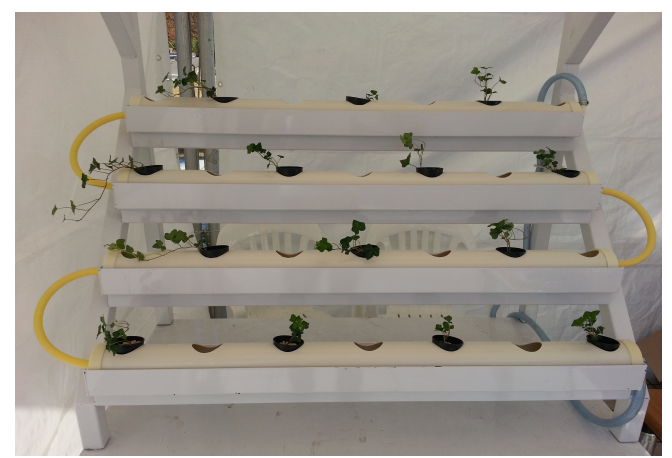

그림 12. 제안하는 수경재배기 모형

Fig. 12 Proposed water culture device prototype

기존 수경재배기 연구가 일자형 다단구조를 중심으 로 진행되면서 작물의 전체적인 광합성 작용 및 영양 분 공급이 부족하다는 단점이 지적되어 본 연구에서 는 피라미드형태의 다단구조 형태를 제안하였다.

\subsection{2. 광원 트래킹 모듈}

광원 트래킹 모듈에 부착된 피라미드 모형은 본 논 문에서 제안하는 수경재배 제어 관리 시스템을 축소 한 모형으로 광원 트래킹을 위해 설계한 테스트베드

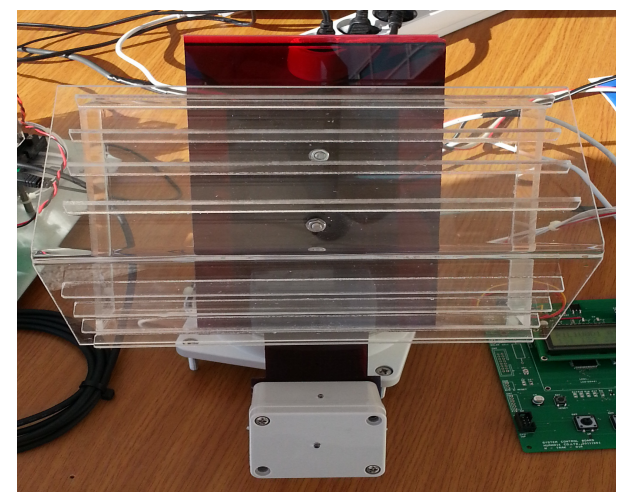

그림 13. 광원 트래킹 모형(정면)

Fig. 13 Solar light tracking prototype(front)

이다. 그림 13은 광원 트래킹 모듈의 정면부로 하단에 위치한 사각형 모형의 박스가 광센서를 부착한 센서 모듈이며 5 개의 광센서를 기반으로 태양광을 추적하
고 작물은 최적의 광합성 작용을 받게 된다. 광원추적 을 위해 하단에 설계된 이동모터는 상하좌우로 움직 일 수 있도록 하였다.

그림 14는 수경재배 제어 관리 시스템의 트래킹 CPU Board이다. 하드웨어 패널의 내부에는 광원 트 래킹 데이터 제어 송 - 수신을 위한 통신 모듈, 원격지 에서 트래킹 정보를 확인할 수 있는 LCD Display, 수 동 및 자동모드를 제어할 수 있는 제어버튼, 광 제어 모듈 등을 포함하고 있다.

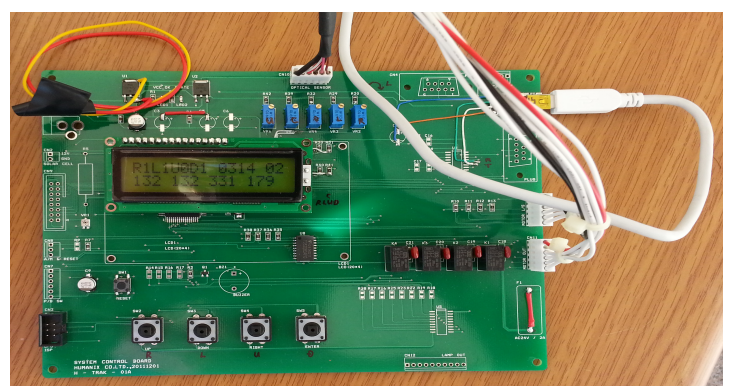

그림 14. 광원 트래킹 모듈 컨트롤 보드

Fig. 14 Solar light tracking module control board

\section{3. 수경재배 제어 시스템 GUI}

수경재배 제어 관리 시스템의 GUI는 웹 인터페이 스와 모바일 인터페이스로 분류되며, 각 인터페이스에 서는 수경재배기의 작물 환경 데이터를 실시간으로 확인할 수 있으며, 센서 제어 및 광원 트래킹 모듈의 제어가 가능하다. 그림 15 는 웹 인터페이스의 메인화

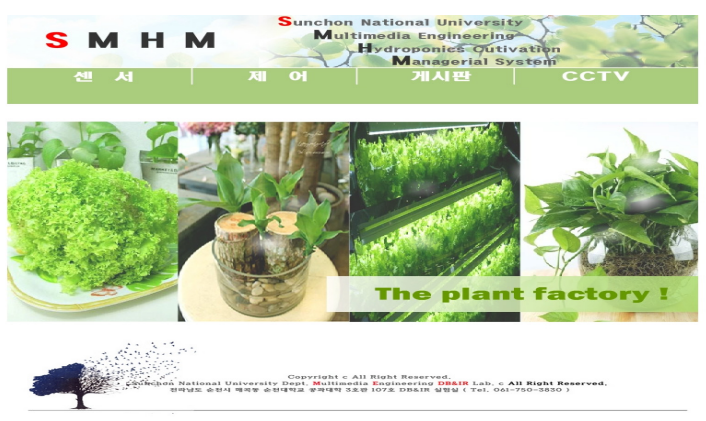

그림 15. 웹 인터페이스(메인화면)

Fig. 15 Web interface(main GUI)

면이며, 그림 16 은 웹 인터페이스의 제어화면으로 펌 프, 트래킹, 히터에 대한 정보를 확인한 후 하드웨어 
에 대한 제어가 가능하도록 하였다. 펌프 및 히터제어 는 히터센서를 기반으로 수동제어가 가능한 11 코드, 자동제어가 가능한 22 코드로 구분된다. 트래킹제어는 자동제어 코드인 02로 처리되며, 수동제어 코드는 01 로 설정된다.

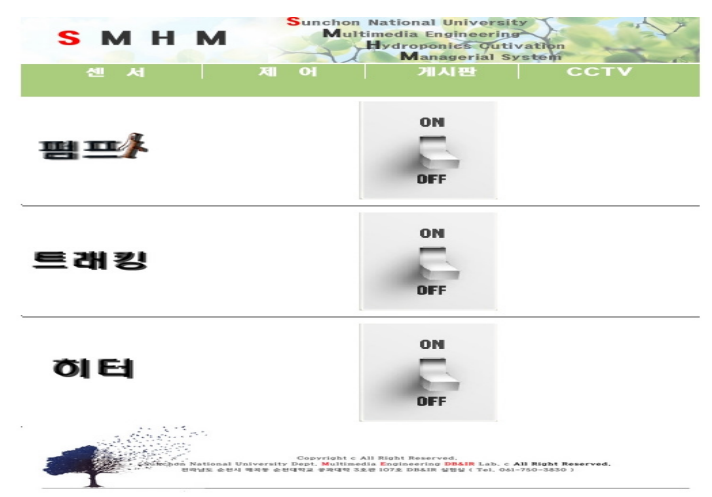

그림 16. 웹 인터페이스(제어)

Fig. 16 Web interface(control)

수경재배 제어 관리 시스템의 모바일 인터페이스는 웹 인터페이스와 같은 기능으로 구성되어있다. 그림 17 은 모바일 인터페이스의 로그인화면이다. 그림 18은 수경재배기에서 재배되는 작물의 생육 환경 데이터 관찰과 병해충 정보를 입력하고 관리할 수 있는 모바 일 작물 관찰일지이다.

\section{- S.M.H.M.}

수경 재배기

\section{관리 프로그램}

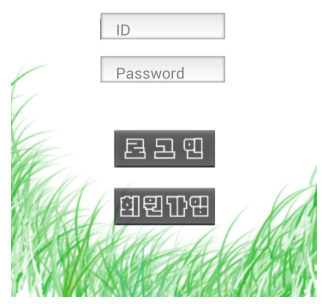

그림 17. 모바일 인터페이스(메인화면)

Fig. 17 Mobile interface (main GUI)
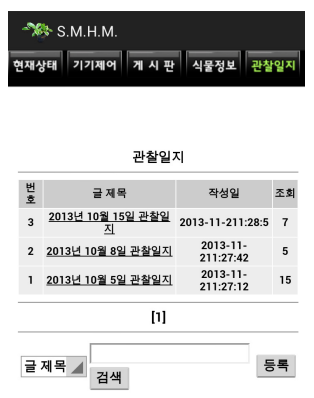

그림 18. 모바일 인터페이스(관찰일지)

Fig. 18 Mobile interface (observation diary)

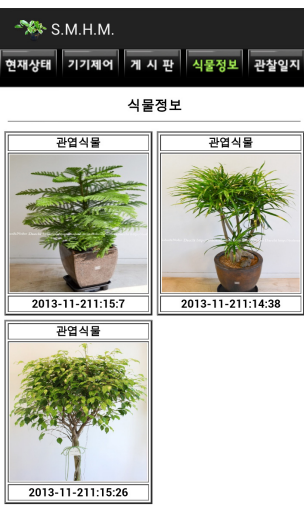

그림 19. 모바일 인터페이스(식물정보)

Fig. 19 Mobile interface (plants information)

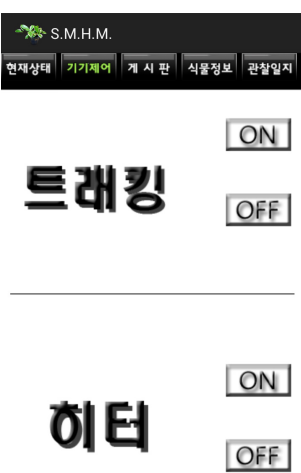
인터페이스(H/W 제어) Fig. 20 Mobile interface (H/W control)
그림 20. 모바일

\section{4. 타 연구와의 정성평가}

현재 자연재해 및 기후 변화로 인한 작물 가격의 변동차가 커짐으로써 소규모 면적에 다량의 생산량을 실현할 수 있는 실내의 식물공장 및 수경재배기에 대 한 연구가 지속되고 있으며 대학, 연구소 등을 중심으 로 관련 연구가 제안되고 있다. 이에 본 연구에서는 수경재배 관리 시스템을 제안하였고 담액수경방식 및 흘림방식을 결합한 새로운 수경재배방식을 제안하였 다. 또한 LED 파장 제어를 통한 작물 최적 환경 생 육 환경 구축 및 태양광 또는 인광원의 지속적인 흡 수를 위한 트래킹 기술, 각종 제어 기술을 제안하였 다. 기존 연구의 목적은 식물공장용 통합 센서 보드와 같은 하드웨어[9-10]를 연구하고 있는 실정이다. 또한 기존 수경재배기의 영양분 공급 방식은 일정량의 영 양분을 공급하도록 고여 있는 형태의 담액수경방식과 일정량의 물을 흘려 재배하는 흘림방식이 각각 연구 되고 있는 실정이다[9]. 표 2는 2장에서 언급한 수경 재배 시스템의 관련연구에서 제시한 시스템들과 본 연구에서 제안하는 시스템과의 비교 분석을 통해 작 
성한 정성평가 표이다.

표 2. 기존 연구와의 정성적인 비교평가

Table 2. Qualitative comparison evaluation with existing study

\begin{tabular}{|c|c|c|c|}
\hline Division & $\begin{array}{c}\text { Study of } \\
\text { [7] }\end{array}$ & $\begin{array}{c}\text { Study of } \\
{[8]}\end{array}$ & $\begin{array}{l}\text { Study of } \\
\text { proposed }\end{array}$ \\
\hline $\begin{array}{l}\text { Pur } \\
\text { pose }\end{array}$ & $\begin{array}{l}\text { Control } \\
\text { System }\end{array}$ & $\begin{array}{l}\text { Monitoring } \\
\text { System }\end{array}$ & $\begin{array}{l}\text { Control } \\
\text { Monitoring } \\
\text { System }\end{array}$ \\
\hline $\begin{array}{c}\mathrm{S} / \mathrm{W} \\
\text { Design }\end{array}$ & $\mathrm{X}$ & $\mathrm{X}$ & UML \\
\hline $\begin{array}{l}\text { Communi } \\
\text { cation }\end{array}$ & Relay, I2C & CDMA & Wifi, USB \\
\hline $\begin{array}{l}\mathrm{H} / \mathrm{W} \\
\text { Type }\end{array}$ & $\begin{array}{l}\text { Multiple } \\
\text { Stage }\end{array}$ & $\begin{array}{l}\text { Multiple } \\
\text { Stage }\end{array}$ & Pyramid \\
\hline $\begin{array}{l}\text { Trac } \\
\text { king }\end{array}$ & $\mathrm{X}$ & $\mathrm{X}$ & $\mathrm{O}$ \\
\hline GUI & $\begin{array}{l}\text { Admin. } \\
\text { (MFC) }\end{array}$ & $\begin{array}{l}\text { Admin. } \\
\text { (Web) }\end{array}$ & $\begin{array}{l}\text { Admin. } \\
\text { (Web, } \\
\text { Mobile) }\end{array}$ \\
\hline
\end{tabular}

\section{V. 결 론}

본 논문에서는 작물의 단위 생산성 향상과 지속적 인 광합성 작용에 관한 기존 연구들의 문제점을 해결 하고자 피라미드식 다단구조 수경재배기 구축과 5축 센서 방식을 활용한 광원 트래킹 모듈을 설계 및 구 현하였다. 또한 수경재배기에 부착된 작물 생육 환경 데이터를 실시간으로 확인하고 센서 제어를 위한 모 바일 및 웹기반의 제어 관리 시스템을 구현하였다. 특 히 수경재배기를 통해 작물의 지속적인 광합성 작용 을 위하여 5 개의 광센서를 이용한 직육면체상의 5 개 면을 활용하였다. 4 개의 면에는 광센서를 부착하여 태 양광의 광량이 비추는 면과 1 개의 면에는 그림자가 생기는 반대면의 광량을 비교하여 일정값이 넘어갈 경우 그림자가 생성되는 광센서의 반대편으로 피라미 드 구조물이 움직이도록 구현하였다.
향후 연구로는 지속적인 태양광의 입사가 작물의 내성에 미치는 영향과 광원 트래킹의 시스템의 움직 임 및 진동이 재배되는 작물의 내성에 미치는 영향도 병행하여야 할 것이다.

\section{감사의 글}

본 논문은 중소기업청에서 지원하는 2013년도 산학 연공동기술개발사업(No. C0124761)의 연구수행으로 인한 결과물임을 밝힙니다.

\section{참고 문헌}

[1] D. Ryu, "A Development of Urban Farm Management System based on USN," J. of Korea Institute of Electronic Communication Science, vol. 8, no. 12, 2013, pp. 1917-1922.

[2] D. Kim, B. Kim, and S. kim, "Ubiquitous sensor network-based LED lighting plant system deployment and integration of research on the operation," The Academic Conf. of the Korean Institute of Illuminating and Electrical Installation Engineers, 2012, pp. 13-15.

[3] I. Jung, S. Kang, B. Lee, and J. Kim, "Plant growth evaluation using a wavelength control LED system and the photovoltaic power," The Academic Conf. of the Korean Solar Energy Society, vol. 33, no. 1, 2013, pp. 124-129.

[4] K. Kim and E. Kim, "Cycle-by-Cycle Plant Growth Automatic Control Monitoring System using Smart Device," J. of Korea Institute of Electronic Communication Science, vol. 8, no. 5, 2013, pp. 745-750.

[5] K. Kim, K. Park, J. Kim, M. Jang, and E. Kim, "Establishment of Web-based Remote Monitoring System for Greenhouse Environment," J. of Korea Institute of Electronic Communication Science, vol. 6, no. 1, 2011, pp. 77-83.

[6] S. Jung, Y. Kwon, and C. Sim, "An Efficient Car Management System based on an Object- 
Oriented Modeling using Car Number Recognition and Smart Phone," J. of Korea Institute of Electronic Communication Science, vol. 7 no. 5, 2012, pp. 1153-1164.

[7] C. Sim, S. Jung, and K. Kim, "ObjectOriented Modeling based on UML for Integrated Manufacturing Management System using Web," J. of Korea Institute of Electronic Communication Science, vol. 5 no. 6, 2012, pp. 602-612.

[8] K. Han, T. Han, S. Lee, and S. Han, "The development of solar tracking sensor and controller for improvement of generation efficiency," J. of the Korean Solar Energy Society, vol. 32, no. 6, 2012, pp. 29-36.

[9] K. Jo, "Establishment of a complete control type plant factory using an integrated controller," Chungbuk University A Master's Thesis, 2013.

[10] Y. Park, "A development of a plant factory monitoring system using renewable energy," Kwandong University A Master's Thesis, 2013.

[11] M. Oh, S. Park, S. Jung, D. Park, and C. Sim, "A Design of Pyramid Type Aquiculture Management System based on LED using Object-Oriented Design Method," The Academic Conf. of Korea Institute of Electronic Communication Science, vol. 7, no. 2, 2013, pp. 139-143.

\section{저자 소개}

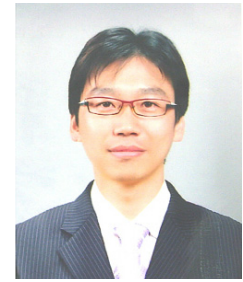

\section{박성균(Sung-Kyun Park)}

2002년 2월 진주산업대학교 전자 공학과 졸업(공학사)

2014년 2월 순천대학교 대학원 멀 티미디어공학과 재학(공학석사)

(주) 휴머닉스 대표이사

※ 관심분야 : $\mathrm{MCU}$ 설계, 신재생 에너지, RFID/USN 응용

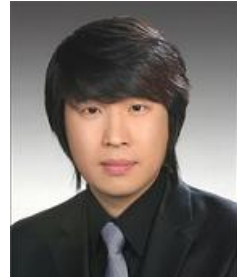

\section{정세훈(Se-Hoon Jung)}

2010년 2월 순천대학교 멀티미디 어공학과 졸업(공학사)

2012년 2월 순천대학교 대학원 멀 티미디어공학과 졸업(공학석사)

2012년 3월 순천대학교 대학원 멀티미디어공학과 재학(박사과정)

※ 관심분야 : 객체지향 모델링, 상황인식

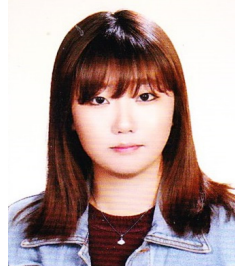

\section{오민주(Min-Joo Oh)}

2014년 2월 순천대학교 멀티미디 어공학과 졸업(공학사)

2014년 3월 현재 순천대학교 대학 원 멀티미디어공학과(석사과정)

※ 관심분야 : 웹 네트워크 통신

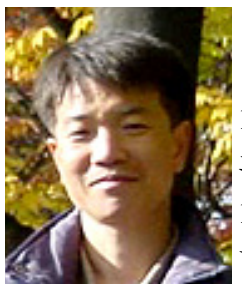

\section{박동국(Dong-Gook Park)}

1986년 2월 경북대학교 전자공학 과 졸업(공학사) 1989년 2월 KAIST 전기및전자공 학과 졸업(공학석사)

2001년 호주 QUT(Queensland Univ. of Tech.) School of Data Communications(공학박사)

2004년 현재 순천대학교 정보통신공학과 부교수 ※ 관심분야 : 정보보호, 보안 시스템, 보안 기법 및 유비쿼터스 컴퓨팅

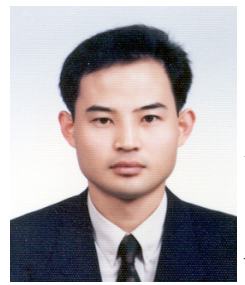

\section{유강수(Kang-Soo You)}

1991년 2월 전북대학교 컴퓨터공 학과 졸업(공학사)

1994년 2월 전북대학교 대학원 컴 퓨터공학과 졸업(공학석사)

2005년 2월 전북대학교 대학원 영상공학과 졸업(공 학박사)

전주대학교 교양학부 교수

※ 관심분야 : 영상처리, 컴퓨터비전, 멀티미디어시 스템, RFID/USN 응용 


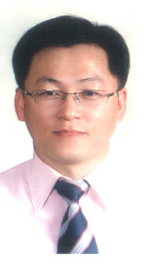

\section{심춘보(Chun-Bo Sim)}

1996년 2월 전북대학교 컴퓨터공 학과 졸업(공학사)

1998년 2월 전북대학교 대학원 컴 퓨터공학과 졸업(공학석사)

2003년 2월 전북대학교 대학원 컴퓨터공학과 졸업 (공학박사)

2005년 현재 순천대학교 멀티미디어공학과 부교수 ※ 관심분야 : 멀티미디어 $\mathrm{DB} \& \mathrm{IR}, \mathrm{RFID} / \mathrm{USN}$, 시스템 모델링, 빅데이타 시스템 